\title{
Effect of Niobium and Titanium Addition on Formation of Second Phase Particles in CHQ Steel Using Transmission Electron Microscope
}

\author{
Shahid Hussain Abro ${ }^{1}$ \\ RECEIVED ON 25.03.2019, ACCEPTED ON 26.07.2019
}

\begin{abstract}
It is common practice that formation of second phase particles such as nitrides or carbides in the steel matrix has significant role to control the grain size of steel. An attempt is made in the present research work to find out the role of nitrogen to form the nitride particles either with Al, Ti, B, Cr or Si. Two steel samples Steel-A and Steel-B with same titanium and aluminum weight percent in the chemical composition were obtained in hot rolled conditions from international market with only the difference of presence of Niobium in Steel-A. Solution heat treatment was performed at $1350^{\circ} \mathrm{C}$ with 60 minutes holding time in protherm heat treatment furnace available locally was used to dissolve the particles and then steel samples were reheat treated at $800^{\circ} \mathrm{C}$ with holding time of 60 minutes and water quenched and microstructure was revealed. Transmission electron microscope connected with Ehlers-Danlos Syndrome (EDS) was used to reveal the morphology of second phase particles. Both samples for a high resolution power Transmission Electron Microscopy (TEM) (Jeol JEM 3010) analysis were prepared by using carbon extraction replica method in 5\% Nital solution as an etching technique. Both samples were then caught in copper grid of $3 \mathrm{~mm}$ for using TEM analysis. TEM micrographs clearly revealed the second phase particles in the matrix of steel. The EDS peaks were studied and it was found that the peaks showed the titanium peaks in both the samples $A$ and $B$ and surprisingly there was no any peak found for aluminum. Stoichiometric calculations were carried out and it was found that weight percent nitrogen required for forming TiN is 0.0073 , however the total nitrogen present in both the steels $\mathrm{A}$ and $\mathrm{B}$ is $\mathbf{0 . 0 0 5 8}$ and 0.0061 respectively. That means that all the nitrogen present in the steel matrix was consumed by titanium to form the Titanium Nitride (TiN) so there was no nitrogen remain to fulfil the requirement of aluminum to form the Aluminum Nitride (AIN) particles.
\end{abstract}

Keywords: Cold Heading Quality Steel, Second Phase Particles, Transmission Electron Microscopy, Niobium.

\section{INTRODUCTION}

$\mathrm{T}$ The Cold Heading Quality (CHQ) steels are assumed to be non-heat treatable so strengthening by cold forming which is a quick and mass production makes these steel a low cost solution for various applications. The microalloying addition of various elements, especially $\mathrm{Al}$, has significant effect on the quality of CHQ steel. With respect to addition of $\mathrm{Ti}, \mathrm{Nb}$ or $\mathrm{V}$ aluminum nitride and their precipitation in steel the precipitation of AIN has strongly influence on end mechanical properties. Due to difficulty in forming precipitates, of AlN, it is unavoidable to produce thermo-mechanical treatment to give rise to accelerate the precipitation kinetics. Gong et al.[1] studied the dissolution and precipitation behaviour in micro alloyed steels of $\mathrm{Nb}$ steel and $\mathrm{Nb}$ $\mathrm{Ti}$ steel, both steels indicated the dissolution of $\mathrm{Nb}$ in austenite upon reheating in both the $\mathrm{Nb}$ and $\mathrm{Nb}-\mathrm{Ti}$ steels but the dissolution was faster for $\mathrm{Nb}$ steel as

${ }^{1}$ Department of Materials Engineering, NED University of Engineering and Technology, Karachi, Sindh, Pakistan. Email: engrabro@neduet.edu.pk

This is an open access article published by Mehran University of Engineering and Technology, Jamshoro under CC BY 4.0 International License. 
compared to the $\mathrm{Nb}-\mathrm{Ti}$ steel. Titanium micro-alloying when adding to $\mathrm{Nb}$ contained steel result in a substantial increase of the yield strength due to refinement of grains, contribution of precipitation hardening was small [2]. Strain plays an important role in precipitation of $\mathrm{Nb}-\mathrm{Ti}-\mathrm{V}$ steel [3]. In high $\mathrm{Nb}$ steel the $\mathrm{Nb}$ does not completely dissolve in the reheating processes, the un-dissolved precipitates act as heterogeneous nucleation sites for the strain induced precipitates [4]. Carbon and manganese can also effect the precipitates sizes in high $\mathrm{Nb}$ steels [5]. Addition of $\mathrm{Nb}$ can significantly improve the impact toughness of $25 \mathrm{CrMo} 48 \mathrm{~V}$ steel due to grain refinement and final martensitic structures [6]. Different other researchers have also studied the various aspects of $\mathrm{Nb}$ addition in steel [7-17]. None of anyone has studied this effect in CHQ steels.

In this research work effect of $\mathrm{Nb}$ addition of precipitation behaviour of micro alloyed CHQ steel is carried out to study the nature of precipitated formed when other elements such as $\mathrm{Al}, \mathrm{Si}, \mathrm{Ti}$ and $\mathrm{Cr}$ are also present. The sample also contains small quantity of Nitrogen.

\section{EXPERIENTIAL PROCEDURE}

\begin{tabular}{|c|c|c|c|c|c|c|c|c|c|}
\hline \multicolumn{10}{|c|}{ Table 1: Composition of Alloy A and Alloy B } \\
\hline Steel & $\mathrm{C}$ & $\mathrm{Mn}$ & $\mathrm{Al}$ & $\mathrm{Ti}$ & $\mathrm{Nb}$ & $\mathrm{B}$ & $\mathrm{N}_{2}$ & $\mathrm{Si}$ & $\mathrm{Cr}$ \\
\hline $\mathrm{A}$ & 0.202 & 1.04 & 0.042 & 0.025 & 0.047 & 0.0018 & 0.0058 & 0.25 & 0.144 \\
\hline $\mathrm{B}$ & 0.2 & 1.04 & 0.042 & 0.025 & - & 0.0019 & 0.0061 & 0.251 & 1.21 \\
\hline
\end{tabular}

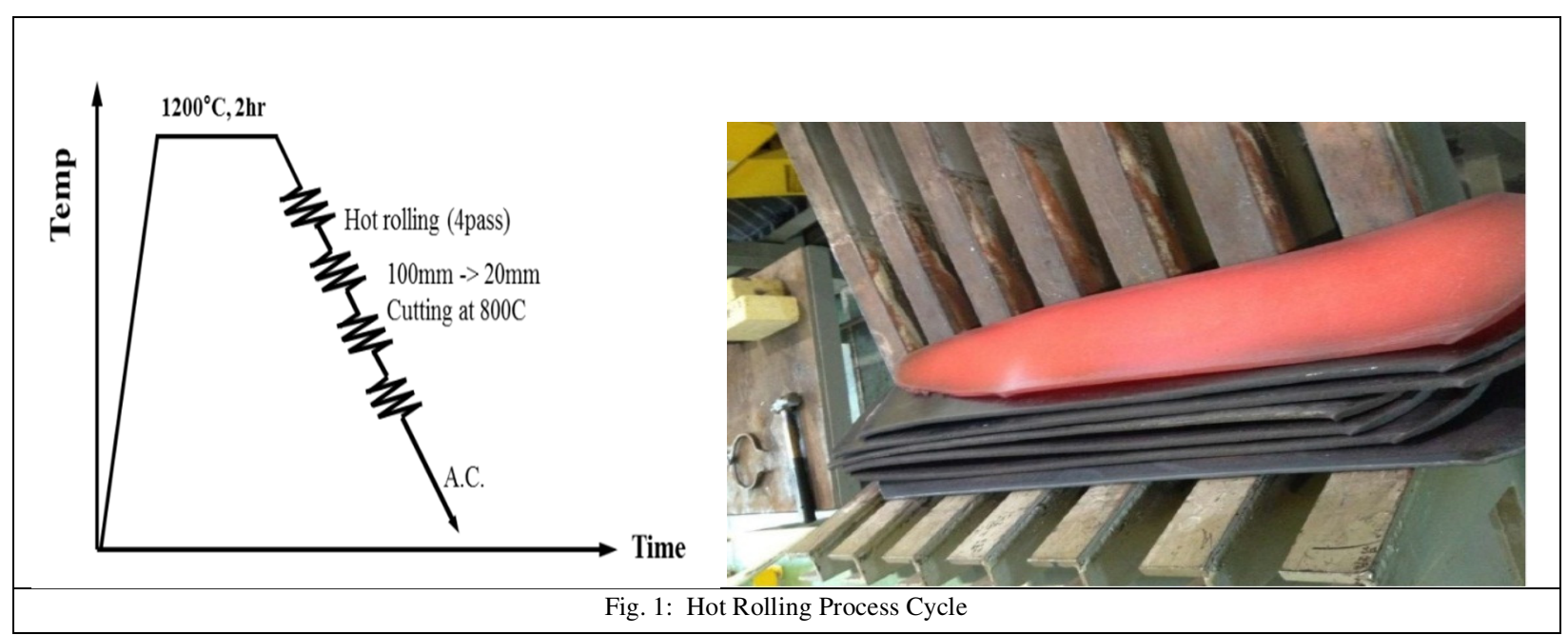

Mehran University Research Journal of Engineering and Technology, Vol. 40, No. 1, January 2021 [p-ISSN: 0254-7821, e-ISSN: 2413-7219] 
After hot rolling both samples A and B were solution heat treated at $1350^{\circ} \mathrm{C}$ and 60 minutes holding time in order to dissolve the particles in the solution at elevated temperature, if present any. After holding, samples were fast cooled in tap water. To investigate the effective influence of particles, both the samples were re-heated at moderate temp: of $800^{\circ} \mathrm{C}$ for one hour and then quenched. After the heat treatment process the samples were then brought to reveal the microstructures with utilizing the conventional grinding and polishing steps followed by etching in $2 \%$ Nital, all the metallography steps were performed locally, Optical microscope Olympus 1000x. Immediately after using optical metallurgical microscope to investigate the microstructures of the Sample-A and Sample-B. Both samples were further prepared for TEM by using carbon extraction replica method, as shown in Figs. 2-3.

\section{RESULTS AND DISCUSSION}

Optical Micrographs of Sample-A as visible in Fig. 4 at $800^{\circ} \mathrm{C}$ and $1350^{\circ} \mathrm{C}$, which indicated that for lower temperature of $800^{\circ} \mathrm{C}$, the grain size is small as compared to the sample at $1350^{\circ} \mathrm{C}$. It is to be noted that second phase particles can only be seen at higher magnification which is not possible for optical micrographs. The particles that were shown in the Sample-A might be oxide particles or some other inclusions. Similar trend was found in Sample-B, Figs. 5-6 in SEM.

The TEM analysis in Fig. 7 shows the particles in Sample-A as revealed through carbon replica method. It was found that particles are in the range of Nano meters with the morphology of square, rectangular, or and some small particles were also showing spherical shape. It was found from TEM analysis in the Steel-A, that contain $\mathrm{Nb}$, the precipitates are showing presence of $\mathrm{Nb}$ as well as $\mathrm{Ti}$, while there was no evidence of $\mathrm{Si}$, $\mathrm{Al}$ and $\mathrm{Cr}$ in EDS peaks.
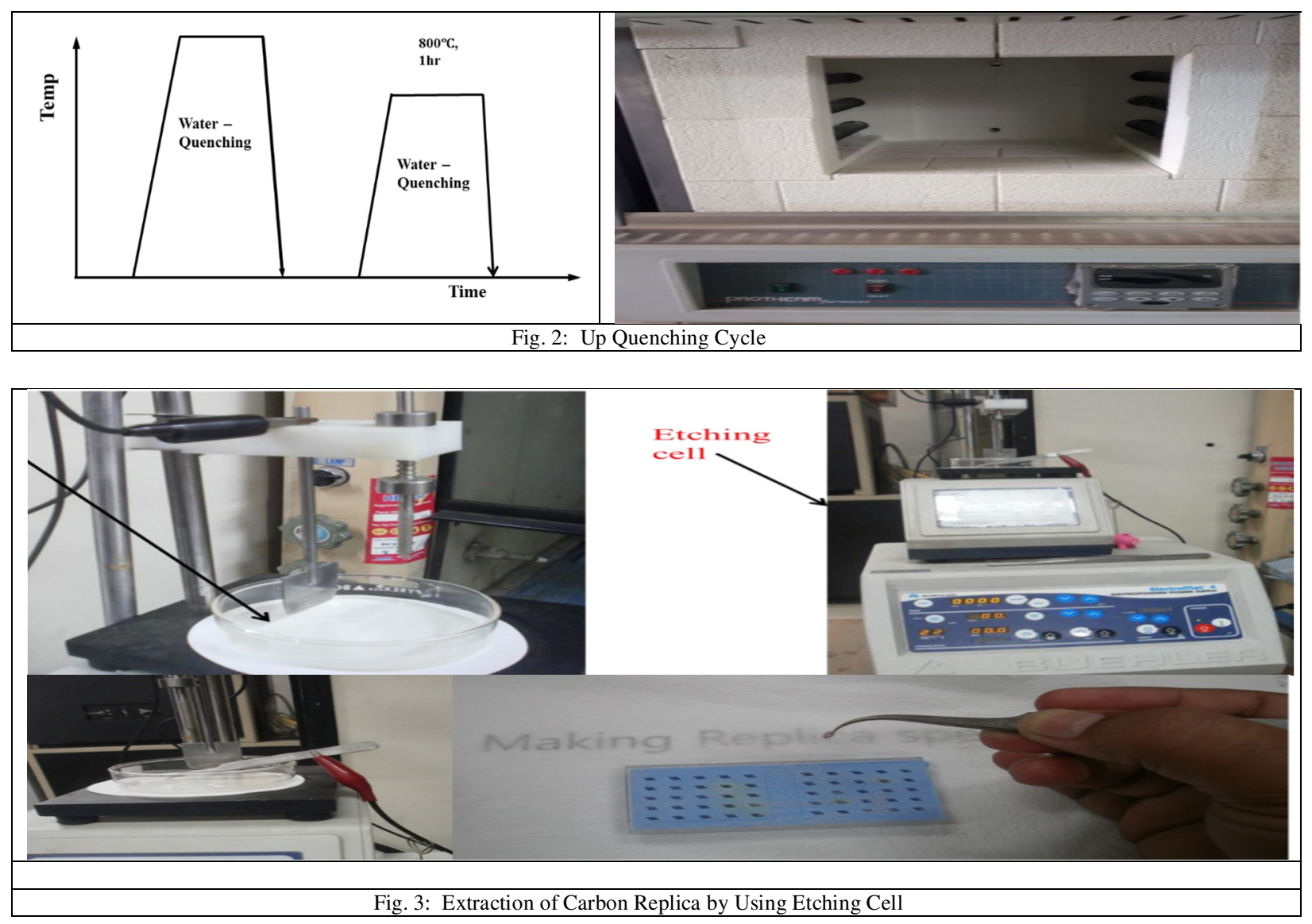

Mehran University Research Journal of Engineering and Technology, Vol. 40, No. 1, January 2021 [p-ISSN: 0254-7821, e-ISSN: 2413-7219] 

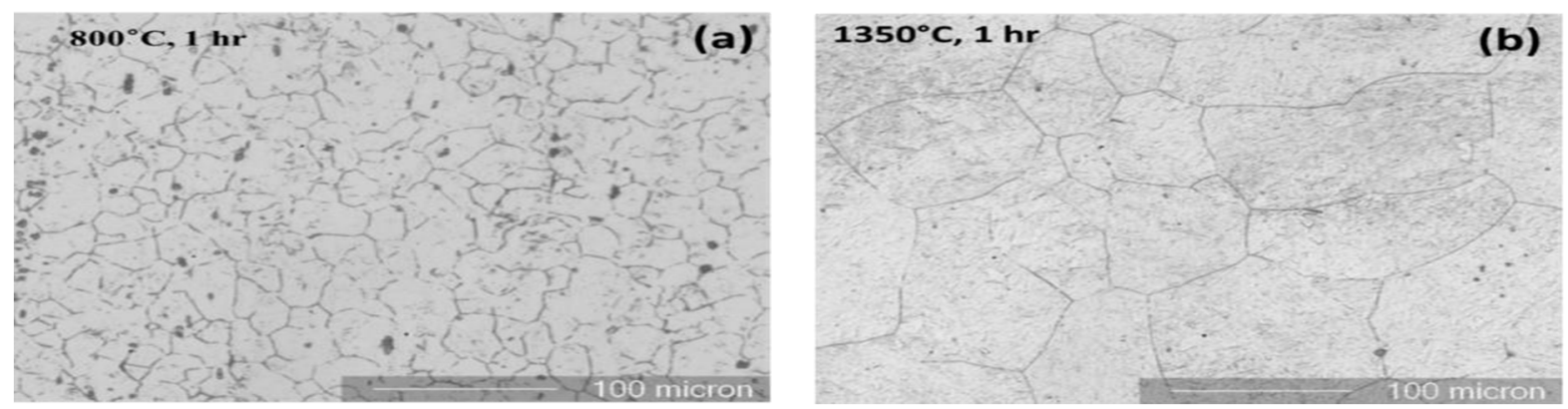

Fig. 4: Optical Micrographs of Sample-A at (a) $800^{\circ} \mathrm{C}$ and (b) $1350^{\circ} \mathrm{C}$
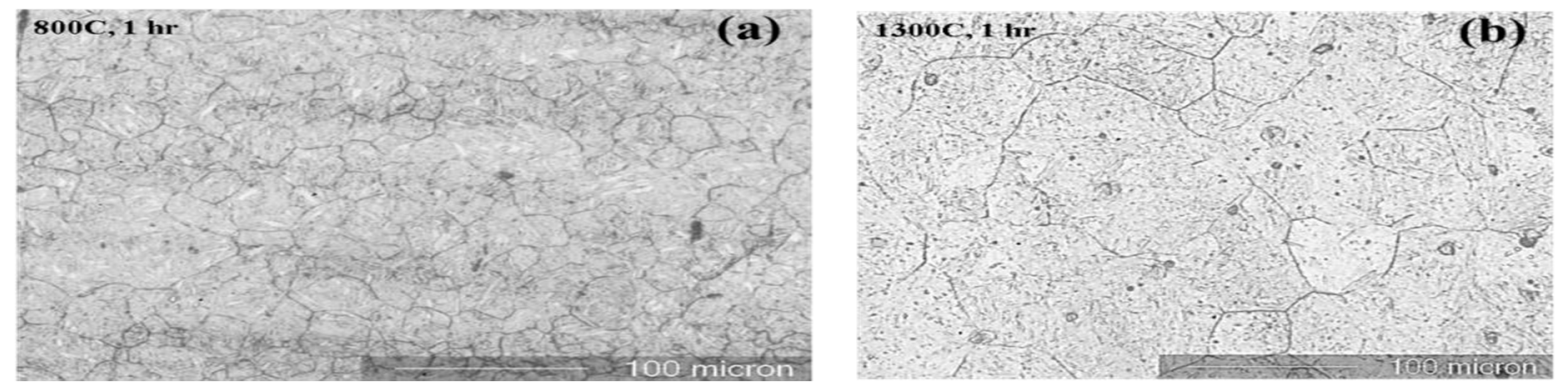

Fig. 5: Optical Micrographs of Sample-B at (a) $800^{\circ} \mathrm{C}$ and (b) $1350^{\circ} \mathrm{C}$
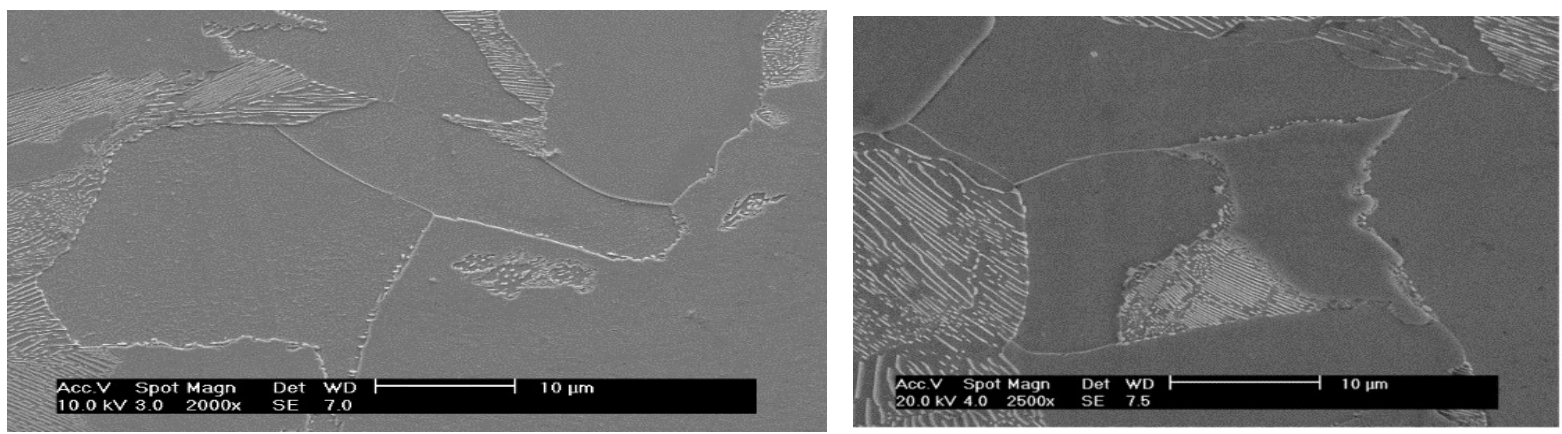

Fig. 6: Initial Sem Micrograhs of Steel-A and Stee-B having Nb and without Nb
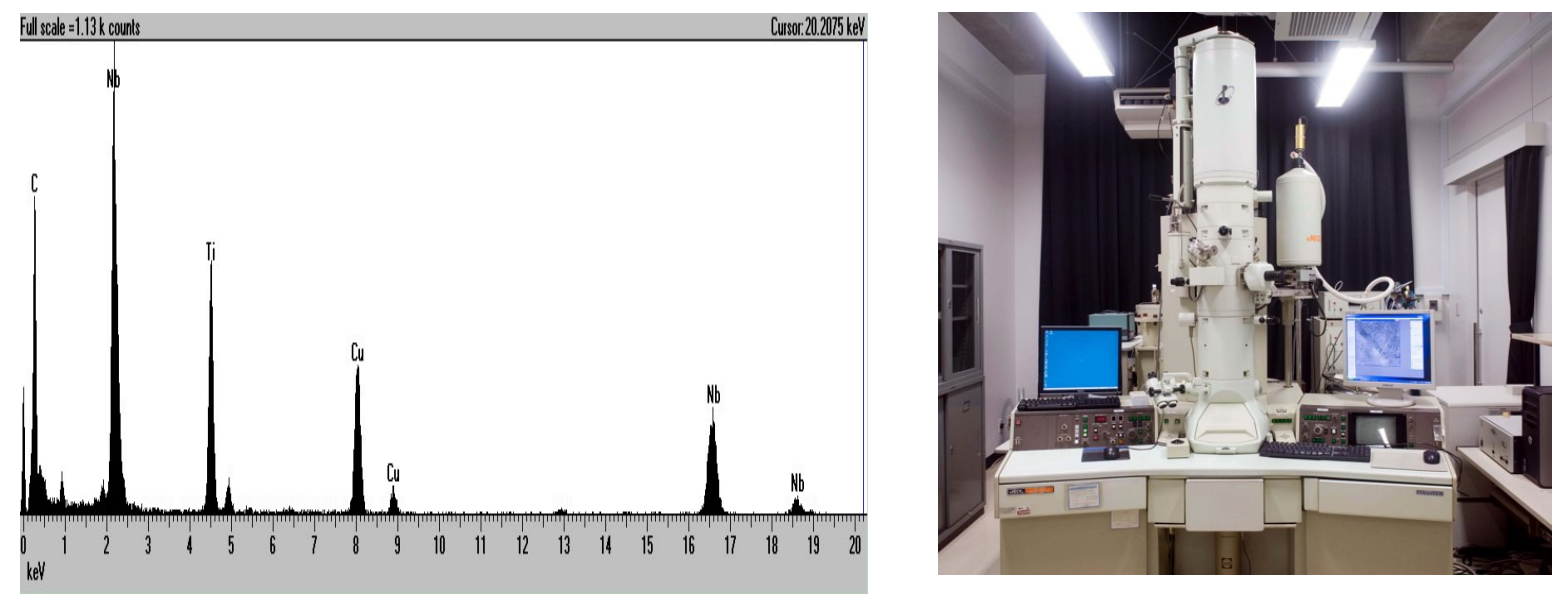

Fig. 7: TEM Micrographs for Sample A. EDS Peaks are shown as well 


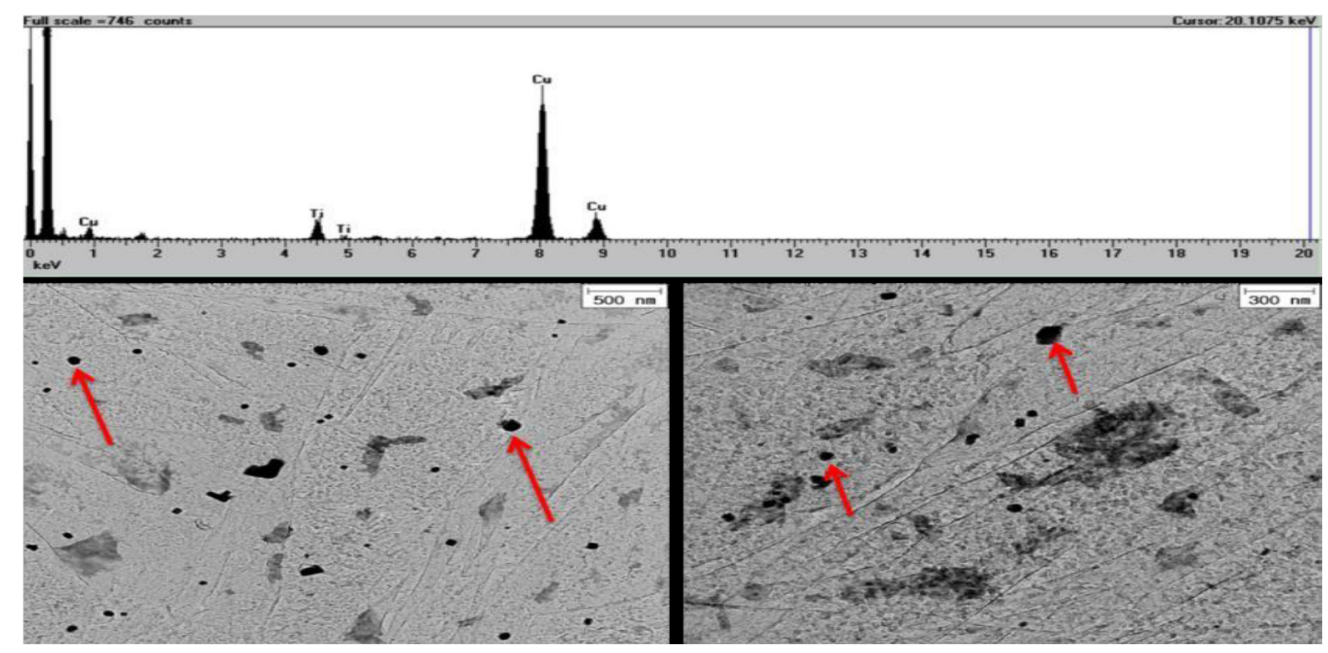

Fig. 8: TEM Micrographics with EDS for sample B

Etching is an important step in this technique, usually etching is performed in the range of $3-5 \%$ nital solution because in the steel matrix, precipitates are existing therefore it is necessary to etch the steel matrix with etchant $(5 \%$ Nital) to drag the particles outside. Care should be taken that the surface should be little over etched. The particles were then kept in the copper grid usually used for TEM analysis. After catching the particles for both Steel-A and Steel-B, samples were then ready for TEM observation. TEM connected with the EDS, is a powerful instrument to reveal the second phase particles as shown in Fig. 8, and the arrows showed in the TEM micrographs are showing the second phase particles. In case of Steel$\mathrm{B}$, where $\mathrm{Nb}$ was not present, precipitates of $\mathrm{Ti}$ were only present without any trace of $\mathrm{Si}, \mathrm{Al}$ and $\mathrm{Cr}$ as shown in the EDS peaks. TEM micrographs clearly reveal the Nano sized second phase particles in the matrix of steel. EDS peaks were studied and it was found that the peaks showed the titanium peaks in both the Sample-A and Sample-B but the Nb peaks were found in the Sample-A only and surprisingly there was no any peak found for aluminium. Stoichiometric calculations were carried out as shown in Table 2 and Figs. 9-10, it was found that weight percent nitrogen required for forming TiN is 0.0073 , however the total nitrogen present in both the steels A and B is 0.0058 and 0.0061 respectively that means all the nitrogen present in the steel matrix was consumed by titanium to form the TiN so there was no nitrogen remain to fulfil the requirement of aluminium to form the aluminium nitride particles.

\section{STOICHIOMETRIC ANALYSIS}

Solubility of nitrogen in aluminium and titanium to form AlN and TiN respectively, an isotherm curves were plotted at various temperature ranges from 850$1250^{\circ} \mathrm{C}$ as shown in Fig. 9. By closing look at the Fig. 10 , it was found that wt. $\%$ nitrogen required to form the nitride nano particle at $850^{\circ} \mathrm{C}$ is about 0.0073 (area in the circle) and in the similar way observe in Fig. 9. The nitrogen required to form the AlN precipitates at $850^{\circ} \mathrm{C}$ is less than 0.002 (circled area). By increasing the temperature, the nitride particles become soluble in the matrix.

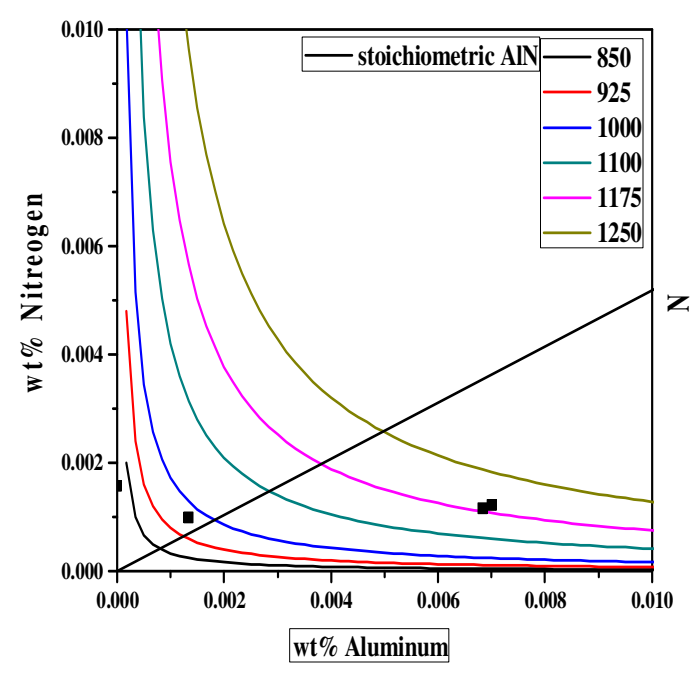

Fig. 9: Stoichiometric Calculations of AL and N 


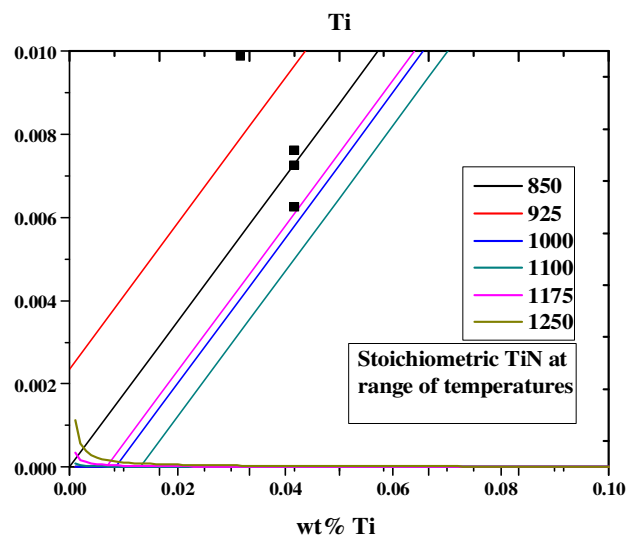

Fig. 10: Stoichiometric Calculations of TI and N

Mathematical calculation was performed to know and verify theoretically the exact amount of nitrogen needed to form the precipitates when nitrogen combines with titanium. The calculation is shown in Table 2. Thermodynamic calculation can also be performed for aluminum with nitrogen $(\log ([\mathrm{Al}][\mathrm{N}])$ $=1.03-6770 / \mathrm{T})$ and titanium with nitrogen $(\log ([\mathrm{Ti}]$ $[\mathrm{N}])=3.82-15020 / \mathrm{T})$.

Table 2: Mathematical Calculation of Ti And $\mathrm{N}$ to form ALN

\begin{tabular}{|c|c|c|}
\hline $\begin{array}{c}\text { Ti Atomic } \\
\text { Mass }\end{array}$ & 48 & wt.\% Ti in Steel-B $=0.025$ \\
\hline $\begin{array}{c}\text { N Atomic } \\
\text { Mass }\end{array}$ & 14 & $(0.025 \times 14) / 48=0.0073$ \\
\hline
\end{tabular}

\section{CONCLUSION}

Effect of Niobium and Titanium addition on formation of second phase particles in CHQ steel using TEM was examined and comparison of two steels with different chemical compositions that contain micro-alloying elements i.e. $\mathrm{Al}, \mathrm{Ti}, \mathrm{B}, \mathrm{Si}$ and $\mathrm{Cr}$ is carried out to study the precipitation behavior of both steels. The Steel-A contains $\mathrm{Nb}$ while the Steel-B does not contain $\mathrm{Nb}$. It was found that in Steel-A the precipitates of $\mathrm{Nb}$ and $\mathrm{Ti}$ were present while in Steel-B only Ti precipitates were present. In both steels none of the alloying elements among $\mathrm{Al}, \mathrm{B}, \mathrm{Si}$ and $\mathrm{Cr}$ showed any formation of precipitates. Stoichiometric calculations were carried out and it was found that weight percent nitrogen required for forming $\mathrm{TiN}$ is 0.0073 , however the total nitrogen present in both the Steel-A and Steel-B is 0.0058 and 0.0061 respectively that means all the nitrogen present in the steel matrix was consumed by titanium to form the TiN so there was no nitrogen remain to fulfill the requirement of aluminum to form the aluminium nitride particles.

\section{ACKNOWLEDGEMENTS}

Authors are greatly thankful to NED University of Engineering \& Technology, Karachi, Pakistan, for providing financial support and Korea Advanced Institute of Science \& Technology, Korea, for providing lab facilities.

\section{REFERENCES}

[1] Gong P., Palmiere E.J., Rainforth W.M., "Dissolution and Precipitation Behavior in Steels Microalloyed with Niobium during Thermomechanical Processing", Acta Materialia, Vol. 97, pp. 392-403, 2015.

[2] Jung J., Lee S.-J., Kim S., De Cooman, B.C., "Effect of Ti Additions on Micro Alloyed Nb TRIP Steel", Steel Research International, Vol. 82, pp. 857-865, 2011.

[3] Jung J.-G., Park J.-S., Kim J., Lee Y.-K., "Carbide Precipitation Kinetics in Austenite of a Nb-Ti-V Microalloyed Steel", Materials Science and Engineering-A, Vol. 528, pp. 5529-5535, 2011.

[4] Cao Y.-B. Xiao F.-R. Qiao G.-Y., Huang C.J., Zhang, X.-B., Wu, Z.-X., and Liao, B., "The Mechanical Behaviour of an Ultrafine Grained $\mathrm{Ti}-47 \mathrm{Al}-2 \mathrm{Cr}$ (at\%) Alloy in Tension and Compression and at Different Temperatures", Materials Science and Engineering-A, Vol. 552, pp. 502-513, 2012.

[5] Karmakar A., Biswas S., Mukherjee S., Chakrabarti D., Kumar V., "Effect of Composition and Thermomechanical Processing Schedule on the Microstructure, Precipitation and Strengthening of $\mathrm{Nb}-$ Microalloyed Steel", Materials Science and Engineering-A, Vol. 690, pp. 158-169, 2017. [6] Ming L., Wang Q., Wang H., Zhang C., Wei Z., Guo A., "A Remarkable Role of Niobium 
Precipitation in Refining Microstructure and Improving Toughness of A QT-Treated 20CrMo47NbV Steel with Ultrahigh Strength", Materials Science and Engineering-A, Vol. 613, pp. 240-249, 2014.

[7] Apps P.J., Bowen J.R., Prangnell P.B., "The Effect of Coarse Second-Phase Particles on the Rate of Grain Refinement during Severe Deformation Processing", Acta Materialia, Vol. 51, pp. 2811-2822, 2003.

[8] Cao Y.-B., Xiao F.-R., Qiao G.-Y., Liao B., "Effects of $\mathrm{Mo}, \mathrm{Cr}$ and $\mathrm{Nb}$ on Microstructure and Mechanical Properties of Heat Affected Zone for Nb-Bearing X80 Pipeline Steels", Journal of Iron and Steel Research International, Vol. 21, pp. 4, 2014.

[9] Cao Y.-B., Xiao F.-R., Qiao G.-Y., Zhang X.B., Liao B., "Quantitative Research on Effects of $\mathrm{Nb}$ on Hot Deformation Behaviors of High-Nb Microalloyed Steels", Materials Science and Engineering-A, Vol. 530, pp. 277-284, 2011.

[10] Cherenda N.N., Uglov V.V., Kuleshov A.K., Astashynski V.M., Kuzmitski A.M., "Surface Nitriding and Alloying of Steels with Ti and $\mathrm{Nb}$ Atoms by Compression Plasma Flows Treatment", Vacuum, Vol. 129, pp. 170-177, 2016.

[11] Niakan H., Najafizadeh A., "Effect of Niobium and Rolling Parameters on the Mechanical Properties and Microstructure of Dual Phase Steels", Advances in Materials Science and Engineering, Vol. 527, pp. 54105414, 2010.

[12] Nöhrer M., Zamberger S., Leitner H., "Strain Induced Precipitation Behavior of a Nb-TiV Steel in the Austenite Phase Field", Steel Research International, Vol. 84, pp. 827836, 2013.

[13] Rajput S.K., Chaudhari G.P., Nath S.K., "Physical Simulation of Hot Deformation of Low-Carbon Ti-Nb Microalloyed Steel and Microstructural Studies", Journal of Materials Engineering and Performance, Vol. 23, pp. 2930-2942, 2014.

[14] Roy S., Karmakar A., Mukherjee S., Kundu S., Srivastava D., Chakrabarti D., "Effect of
Starting Microstructure on Austenite Grain Sizes Developed After Reheating of HSLA Steel", Materials Science and Technology, Vol. 30, 1142-1153, 2013.

[15] Xie K.Y., Zheng T., Cairney J.M., Kaul H., Williams J.G., Barbaro F.J., Killmore C.R., Ringer S.P., "Resolving the Morphology of Niobium Carbonitride Nano-Precipitates in Steel Using Atom Probe Tomography", Scripta Materialia, Vol. 66, pp. 710-713, 2012.

[16] Yuan S.Q., Liang G.L., "Dissolving Behavior of Second Phase Particles in $\mathrm{Nb}-\mathrm{Ti}$ Microalloyed Steel", Materials Letters, Vol. 63, pp. 2324-2326, 2009.

[17] Zhu Y.-Z., Zhu Z., Xu J.-P., "Grain Boundary Segregation of Minor Arsenic and Nitrogen at Elevated Temperatures in a Microalloyed Steel", International Journal of Minerals, Metallurgy, and Materials, Vol. 19, pp. 399403, 2012. 